\title{
IT Governance in Collaborative Networks: A Socio-Technical Perspective
}

\author{
Josephine L.L. Chong \\ Department of Business Information Systems \\ Auckland University of Technology \\ josephine.chong@aut.ac.nz \\ Felix B. Tan \\ Department of Business Information Systems \\ Auckland University of Technology \\ felix.tan@aut.ac.nz
}

\begin{abstract}
Research on IT governance has tended to focus on the issue within a single organizational environment. Our understanding of IT governance in an inter-organizational context remains limited. In addition, few have taken a socio-technical perspective. The aim of the study is therefore to empirically explore the impacts of socio-technical factors on the effectiveness of IT governance for a collaborative network by examining three IT governance elements: structure, process and relational mechanism. This paper reports on the findings of the pilot phase of the broader study. The findings indicate that more effective collaborative IT governance is associated with an active involvement of a governing body; a co-ordinated communication process; and the presence of relational culture and attitudinal commitment. Theoretical and managerial implications of the study are discussed.
\end{abstract}

Keywords: IT governance, Attitudinal commitment, Relational culture, Communication process 


\section{Introduction}

According to Gartner, the worldwide information technology (IT) spending in 2012 is expected to increase from USD 3.7 trillion to USD 3.8 trillion. This annual expenditure growth has underlined the importance of IT as an enabler for organizational success (Kim et al., 2007). Organizations are deploying IT in reinforcing existing business strategies or shaping potential strategies in order to engender sustained competitive advantages. IT facilitates business process re-engineering which often entails cost reduction and process improvements (Sambamurthy and Zmud, 1999; Weill, 2004). As a result, organizations are exploiting IT as a crucial and strategic driver to support and shape their organizational activities. To achieve this, organizations are advised to properly structure and manage IT in order to derive business value from it (Bowen et al., 2007). An aspect of this is IT governance which is needed to drive effective IT management processes that can position the organization to better exploit the business potential of IT (Ali and Green, 2009; Willson and Pollard, 2009).

Typically, the mainstream research on IT governance tends to emphasize the single organization as the unit of analysis (Ali and Green, 2009; Huang et al., 2010; Willson and Pollard, 2009). To date, little research has investigated IT governance in practice within a collaborative network that involves more than two organizations through the utilization of IT (Croteau and Bergeron, 2009; Hekkala et al., 2010). It is an important aspect as many organizations are moving into collaboration due to a competitive and turbulent business environment. As such, the first objective of this study is to enhance our understanding of IT governance in a collaborative network.

There is vast literature emphasizing the contribution of socio-technical approach to the success of an enterprise system. The basis of such approach is to provide a holistic view which considers the interplay between technical and social factors, and how the interaction can have a positive impact on the organi- zational processes that consequently leads to a successful implementation of an enterprise system. For instance, Rycroft and Kash (2002) contend that the coupling between organizational learning and IT processes has a capacity to enhance technological innovation. Similarly, better implementation of an enterprise system can be facilitated when IT training is equally intertwined with IT deployment (Somers and Nelson, 2004). As such, the second objective of this study is to enhance our understanding of the sociotechnical factors that influence the effectiveness of IT governance for collaborative networks.

In addition to the theoretical contributions, this study provides some implications for practice. The practitioners would have a better understanding of how socio-technical factors can enhance the effectiveness of IT governance for a collaborative network. This study emphasizes that a collaborative network needs to cultivate attitudinal commitment so that governance structure can be effectively regulated. Co-ordinated synchronous and asynchronous communication channels would play a role in facilitating the collaborative network's processes. Lastly, as a collaborative network is comprised of several organizations, a relational organizational culture is necessary to manage the relationship perspective of IT governance implementation.

The remainder of this paper is structured as follows. We begin by introducing the theoretical perspectives. Next, the methodology will be discussed. We will present the findings of a case study and illustrate how it is used to examine the socio-technical factors associated with IT governance for a collaborative network. The paper will conclude with discussions of what we have learnt from the case study and the implications for practitioners.

\section{IT Governance Defined}

The concept "IT governance" was introduced in the early nineties but it did not gain a lot of attention. It was only until the late nineties that the notion of IT governance had been a 
focus area for both business practitioners and academics. This was largely attributed to the IT governance studies by Brown (1997) and Sambamurthy and Zmud (1999). Their research highlighted that the type of IT governance arrangements (centralized, decentralized, federal) and the allocation of IT related management responsibilities and decision making rights to the appropriate organizational groups (which comprised of top executives, business units and IT group) would have an impact on the effectiveness of IT management practices. The researchers advocate that strong IT governance enables organizations to fully exploit their investments in IT so that organizational benefits can be realized and maximized.

Over the years, researchers have been building upon the work of Brown (1997) and Sambamurthy and Zmud (1999) to further examine the types of factors or mechanisms that will influence IT governance effectiveness (Ali and Green, 2009; Bowen et al., 2007; Huang et al., 2010). In particular, the literature has identified three characteristics that can have an impact on the effectiveness of IT governance in an organizational context. The first aspect is associated with the structural perspective of IT governance. It focuses on identifying the typical IT governance arrangement for a specific organizational group (Peterson, 2004) a well as the structuring and distributing IT related decision making rights (Brown and Grant, 2005; Weill and Ross, 2004). The second aspect takes a process approach that emphasizes the control and risk features of IT governance. Typically, IT governance researchers (such as Van Grembergen et al., 2003; Merhout and Havelka, 2008) have proposed the use of Control Objectives for Information and related Technology (CoBIT), Information Technology Infrastructure Library (ITIL) and IT Balanced scorecard to provide more detailed guidelines and best practice standards so that better alignment between IT and organizational strategy can be achieved. The last aspect focuses on the relational characteristic of IT governance which entails critical factors such as commitment, involvement and trust (De
Haes and Van Grembergen, 2004; Wilkin and Riddett, 2009).

Various definitions of IT governance have emerged from the three characteristics of IT governance effectiveness. The typical definitions of IT governance are:

- IT Governance Institute emphasizes that "IT governance is the responsibility of the Board of Directors and executive management. It is an integral part of enterprise governance and consists of the leadership and organizational structures and processes that ensure that the organization's IT sustains and extends the organization's strategies and objectives" (IT Governance Institute, 2003, p. 10).

- Weill defines IT governance "as specifying the framework for decision rights and accountabilities to encourage desirable behaviour in the use of IT" (Weill, 2004, p.2).

- Peterson characterizes IT governance as "the distribution of decision-making rights and responsibilities among enterprise stakeholders, and the procedures and mechanisms for making and monitoring strategic decisions regarding IT" (Peterson, 2004, p.3)

- Webb et al. 2006 define IT governance as "the strategic alignment of IT with the business such that maximum business value is achieved through the development and maintenance of effective IT control and accountability, performance management and risk management" (Webb et al., 2006, p. 194a)

These diverse definitions can be categorized into three distinctive perspectives: (1) the allocation of IT related decision making rights and accountabilities within the organization, (2) strategic alignment between IT and organizational strategy and objectives, and (3) the organizational structure of relationships. The first perspective stresses on IT governance structure which involves the identification of decision-making authority and clarification of the roles and responsibilities for making ITrelated decisions. The second perspective 
focuses on how an organization can enact IT in the most effective way so that it can be integrated with the business strategies and objectives (Luftman and Kempaiah, 2008). In order to support the alignment of business objectives and IT, organizations have to manage their IT governance processes to oversee the deployment of their IT resources and implement IT performance measurement. (Bowen et al., 2007; Van Grembergen et al., 2004). The last perspective, as presented by Weill (2004) is concerned about how to "to encourage desirable IT behaviours". It is advocated that appropriate relational mechanisms enable the building of mutual understanding which can encourage better coordination of IT activities. Drawing these arguments together, this paper regards IT governance as a framework in specifying the allocation of IT related decision making rights and responsibilities to the right organizational group and deploying relational mechanisms to support the alignment between business objectives and IT. In an inter-organizational context, IT governance is defined as an accountability framework whereby formal IT decision-making authority has been delegated to a focal organization which will structure the distribution of IT decision making rights and responsibilities among different stakeholders. It enables the alignment of the network's defined goals with the deployment of IT in an effective and efficient manner. Furthermore, the inter-organizational IT governance framework has to incorporate relational mechanisms which play an important role in fostering an effective collaborative partnership.

\section{Social-Technical Approach on IT Governance}

This paper proposes a socio-technical perspective on IT governance. According to Trist (1981), an organizational work system is to be facilitated by both technical and social systems. The technical system refers to the technology that is needed to carry out the organizational tasks while the social system consists of the people who are responsible for carrying out those organizational tasks. IT governance can be envisaged as a sociotechnical system. IT governance process is considered to be technologically constructed because it involves the effective and efficient use of IT resources to support IT strategies and polices in ensuring the alignment of IT and organizational strategy, while IT governance structure and relational mechanisms are related to the social system as they include the roles and responsibilities of different organizational groups and the desirable human behaviours to perform and co-ordinate the organizational work system.

More importantly, the socio-technical approach asserts a joint optimization of social and technical systems can result in a positive impact on organizational performances (Liu et al., 2006). It is advocated that technical and social factors can play a role in the joint optimization of the organizational work system (Trist, 1981). As discussed by Orlikowski and Barley (2001), technical factors can have a positive impact on the efficiency of the technical systems. Such technology factors encompass variables that can be related to the design and analysis of information systems, the techniques and skills of implementation and management of IT processes, studying the diffusion of new technologies, and measuring information systems quality. The authors further described that the way people exploit these technical systems can by influenced by the social factors. These nontechnical factors cover relational and cultural characteristics of the social system.

Prior research has explored how sociotechnical factors can have an effect on IT governance structures, processes and relational mechanisms. For instance, studies have examined the impact of organizational size, appropriate allocation of IT related decision making and a balance of responsibilities and accountabilities between business and IT (Huang et al., 2010; Sambamurthy and Zmud, 1999; Weill, 2004) on IT governance structures. On the other hand, Bowen et al. (2007) and Weill and Ross ( 2004) emphasized that effectively communicated IT strategies and policies and involvement of IT committees can affect the IT governance processes. Last- 
ly, other social factors, such as organizational culture, commitment and collaborative behaviours, also have a great impact on the deployment of relational mechanisms in supporting the alignment between business objectives and IT (Kingsford et al., 2003; Peterson, 2004).

To date, there is little understanding of what influences IT governance in a collaboration context (Croteau and Bergeron, 2009; Hekkala et al., 2010). The authors therefore propose to examine the role of socio-technical factors in the effectiveness of IT governance in a collaborative network.

\section{Collaborative Network IT Gov- ernance}

\section{Collaborative Network and IT Govern- ance}

For this paper, a collaborative network is defined as "a collection of loosely connected or closely knit organizations that share resources" to achieve strategic objectives (Arya and Lin, 2007, p. 698). The importance of collaborative networks can be seen in the attention that they are given in a wide range of disciplines, such as organizational theory and behaviour, strategic management, business studies, healthcare services and public. There are many empirical studies showing that these collaborative networks can provide opportunities for organizations to learn from each other by gathering information and acquiring new skills, knowledge and resources to improve organizational competitiveness in terms of improved products or services, better innovation, enhanced technology and market development (Ahuja, 2000; Hemphill and Vonortas, 2003; Taylor, 2005).

Nowadays, collaborative networks are using various information and communication technology (ICT) such as the Internet, intranets, extranets, knowledge portals, group decision support systems and electronic meeting systems to support their collaborative relationships and to enable them to be more flexible and more networked (Fink, 2007). This growing trend is driven by a range of technological benefits (Fink, 2007; Chi and Holaspple,
2005): (1) reduced communication costs as the exploitation of audio and video conferencing and web conferencing enable communication without face-to-face interaction; (2) enhanced facilitation of knowledge sharing ;(3) increased innovation as ICT improves organizational communication, including the collection, integration, transfer and application of employees' knowledge, amplifying the knowledge base available and its utilisation; and (4) enhanced decision making as the exploitation of decision support systems, electronic document management, and electronic meeting systems facilitates better and quicker decision making related to the allocation and utilization of resources and other organizational strategic issues, ultimately leading to an enhancement in decision quality, better utilization of resources and administrative efficiency.

As ICT plays a critical role in assimilating, disseminating and communicating information and knowledge that is crucial for facilitating the collaborative network's business and operational processes and in order to reap the business values and achieve strategic goals from the deployment of these ICT, collaborative networks need to have good IT governance. According to Weill (2004, p.2), strong governance involves "systematically determining who makes each type of decision, who has input to a decision, and how these people (or groups) are held accountable for their role." That is to say, the effectiveness of IT governance for a collaborative network can be influenced by two aspects: (1) how and by whom IT related decision making rights and responsibilities are distributed; and (2) what relational mechanisms are vital for regulating various stakeholders behaviours so as to ensure the alignment between business objectives and IT is achieved.

The socio-technical perspective of IT governance can be applied to the specific features for effective IT governance in a collaborative network context. This paper views collaborative network IT governance effectiveness as socially constructed as it involves the role and influence of collaborative behaviours in aligning the network's strategic goals with IT. 
More significantly, it has to be reinforced by both technological factors (i.e. ICT infrastructures and communication processes) and social factors (i.e. culture, commitment, strong collaborative relationships).

This paper presents a socio-technical analysis of the three perspectives of IT governance within a collaborative network context: IT governance structure, IT governance process and relational mechanisms. More specifically, it is looking at how socio-technical factors can have an impact on the three aspects of IT governance consequently affecting the collaborative network IT governance effectiveness. Hence, the research questions examined are:

1. How do collaborative networks establish effective IT governance?

2. What socio-technical factors are essential to the effectiveness of IT governance in a collaborative network? How do these factors influence IT governance structures, processes and relational mechanisms?

\section{Research Methodology}

\section{Research Design}

IT governance in a collaborative network context is new phenomenon that lacks of conceptual and theoretical specificity. In such a case, this research was exploratory in nature and given the research questions, a qualitative research approach was adopted (Yin, 2003). As pointed out by Strauss and Corbin (1998), a qualitative approach enables the researcher(s) to gain a better understanding in an under-researched phenomenon. More importantly, it has the capability to explore the views of the participants in ways a quantitative approach cannot. Among the qualitative data collecting methods, a case study research method is the best approach for an exploratory study (Yin, 2003).

This case study design follows a single, exploratory, pilot case study. According to Benbasat et al. (1987), it is appropriate to use a single case study as a pilot study when the research is very exploratory. The strength of a pilot case study is that it enables the researcher to get more familiar with the phenomenon in its context. Indeed, a number of studies have been conducted on the impact of socio-technical factors on intraorganizational IT governance but not much is known of IT governance effectiveness within a collaborative network context. Thus, this pilot case study was designed to explore how a collaborative network could establish strong IT governance and identify what types of social and technological factors were believed to be relevant to collaborative network IT governance effectiveness. The issues identified from this exploratory pilot study can be used as potential and important variables for further investigation.

The pilot case study involved the work of a collaborative network of eight organizations that sought to develop a national Patient Health Portal (PHP) for the New Zealand public. In light of a growing greying population, the PHP engenders tailored care to the aged healthcare consumers by enabling them to effectively manage and maintain their chronic conditions and cardiovascular disease at home. The PHP provides a low-cost means as the healthcare consumers can co-ordinate and choose healthcare services targeting to his/her health status and needs. In addition, hospitals would have a lower rate of acute admissions hence healthcare providers would have a better allocation of the financial human asset resources. The health portal was facilitated by a Portal Adaptor which was connected to a Health Portal Search Engine (a pseudonym). Sequentially, the Health Portal Search Engine (HPSE) would be driven by various adaptors that would be built by collaborative organizations. Each organization would contribute perspective functionality to its adaptor.

The primary form of data collection was through semi-structured interviews with the key representatives from each organization involved in the collaborative network. Altogether, five face-to-face interviews and three telephone interviews were conducted with representatives from six organizations, with an average duration of one hour per interview. 


\begin{tabular}{|c|c|c|}
\hline $\begin{array}{c}\text { Organization } \\
\text { (names are pseudonyms) }\end{array}$ & Roles in the project & Interviewee \\
\hline Health Technology Consortium & $\begin{array}{l}\text { Lead the project and provide govern- } \\
\text { ance through a contractual framework } \\
\text { and funding agreements }\end{array}$ & $\begin{array}{l}\mathrm{CEO}(\mathrm{x} 2) \\
\text { Programme Manager }\end{array}$ \\
\hline Software Company & $\begin{array}{l}\text { Multinational software company acting } \\
\text { as project sponsor and providing ICT } \\
\text { infrastructure including a server envi- } \\
\text { ronment and collaboration software }\end{array}$ & $\begin{array}{l}\text { Health Sector Account } \\
\text { Manager }\end{array}$ \\
\hline ITConsult & $\begin{array}{l}\text { Manage the project and build the health } \\
\text { portal architecture }\end{array}$ & $\begin{array}{l}\text { Project Consultant } \\
\text { Manager }\end{array}$ \\
\hline Primary Health Organization & $\begin{array}{l}\text { Network of primary healthcare practices } \\
\text { responsible for clinical focus in portal } \\
\text { design and user acceptance testing }\end{array}$ & $\begin{array}{l}\text { Chief Information Of- } \\
\text { ficer }\end{array}$ \\
\hline Health Systems Provider A & $\begin{array}{l}\text { Provide the patient management sys- } \\
\text { tem for the portal }\end{array}$ & CEO \\
\hline Health Systems Provider B & $\begin{array}{l}\text { Provide a healthcare decision support } \\
\text { system for specific chronic health condi- } \\
\text { tions }\end{array}$ & $\begin{array}{l}\text { Not available to be in- } \\
\text { terviewed }\end{array}$ \\
\hline Health Information Provider A & $\begin{array}{l}\text { Provide an online tool for consumer } \\
\text { healthcare information and services } \\
\text { search and referrals }\end{array}$ & $\begin{array}{l}\text { Business Development } \\
\text { Manager }\end{array}$ \\
\hline Health Information Provider B & $\begin{array}{l}\text { Provide interactive voice response } \\
\text { coaching for healthcare consumers }\end{array}$ & $\begin{array}{l}\text { Not available to be in- } \\
\text { terviewed }\end{array}$ \\
\hline
\end{tabular}

The organizations and interviewees are shown in Table 1. One organization did not agree to participate in the study and one organization no longer existed at the time the fieldwork was conducted. While the number of interviews is limited, it represents all the primary project participants who were available to be interviewed. The interviews were structured with open-ended questions addressing the roles of various stakeholders and their motivation for participating in the collaborative network; the types of ICT that were deployed in facilitating the business and operational processes; information in relation to the IT governance structures, processes and relational mechanisms; the social- technical factors that impacted on the effectiveness of IT governance.

All of the interviews were tape-recorded and transcribed. The qualitative interview data were thematically analysed. After each interview, simple coding procedures were used to conceptualize the data. Codes were developed that provided the basis for developing initial categories and helped to identify patterns and analyze emerging patterns of themes (Strauss and Corbin (1998). The authors' search for patterns in the collected data using a coding scheme that emphasized on understanding how IT governance was established in the PHP collaborative network and what socio-technical factors were associated with strong IT governance.

To ensure construct validity in the research design, we firstly used multiple sources of information (Yin, 2003) and secondly, selected participants from different functional backgrounds.

The primary source of information was derived from the interviews while some of the interviewees provided supporting secondary data, including the terms of reference for the project and the various roles and responsibilities of each network member, press releases, and web resources. The various functional backgrounds of the interviewees (refer to Table 1) represented an important triangulation of information sources which helped prevent biased opinions (Patton, 1999). However, there is a specific concern with the external validity. The findings could not be generalized as the PHP project was based in a New 
IT Governance in Collaborative Networks: A Socio-Technical Perspective / Chong and Tan

Zealand health context. In order to ensure external validity, further research is required both in other countries and contexts. The authors had maintained a chain of evidence that was to trace the conclusions to the interview summary and to the interview transcripts. According to Yin (2003), this chain of evidence will improve the reliability of the data.

\section{Unit of Analysis}

The unit of analysis is at an interorganizational level as we are concerned with how these collaborative organizations define the network's IT governance. Typically for an organization to achieve effectiveness in its IT governance, it must consider how to distribute the IT decision making in facilitating the IT governance processes, and how to deploy relational mechanisms in bringing the various stakeholders together to co-ordinate the organizational activities and support the business goals. This study explores the mechanisms or factors that are crucial for effective inter-organizational IT governance.

\section{A Priori Constructs}

According to Eisenhardt (1989), a priori specification of constructs enables the shaping of an initial research design, and allows the researchers to measure the constructs more accurately. If these constructs prove important as the study progresses, the researchers have a firmer empirical grounding for the emergent theory (Eisenhardt 1989). From the literature, socio-technical factors that will contribute to or impact on the three aspects of IT governance were identified. Table 2 summarizes the influencing sociotechnical factors.

\section{Socio-Technical Factors Influencing IT Governance Structure}

IT governance structures refer to the type of decision-making arrangement of an organization (De Haes and Van Grembergen, 2004). According to Sambamurthy and Zmud (1999), IT governance's decision-making structures can be categorized into three modes: centralized, decentralized and federal. Centralized IT governance mode is one whereby the corporate information systems (IS) have the authority in making any IS related decisions. Whereas, decentralized IT governance mode is one whereby divisional IS and line managers have the authority in making any IS related decisions. Lastly, federal IT governance mode is one whereby corporate IS, divisional IS and line managers share the authority in making any IS related decisions.

The adoption of an IT governance structure can be determined by the size of the organization (Sambamurthy and Zmud, 1999). For instance, the empirical study of Huang et al. (2010) proposed that if the organization is a small- and medium-sized enterprise (SME), it would be more likely to adopt a centralized IT governance mode. This is because SME is more functionally structured therefore it is more feasible to have a central IS organizational body to make all IS related decisions (Sambamurthy and Zmud, 1999). A centralized IT governance mode enables consistency and standardized controls which consequently would engender better co-ordination of organizational processes and operations. On the other hand, it would be more feasible for a large multi-international organization to adopt a decentralized IT governance mode

\section{Table 2 - Summary of Socio-Technical Factors Influencing}

\begin{tabular}{|l|l|l|}
\hline IT Governance Elements & \multicolumn{1}{|c|}{ Socio-Technical Factors } & \multicolumn{1}{|c|}{ Source } \\
\hline IT Governance Structure & $\begin{array}{l}\text { Organizational Size } \\
\text { IT Governance Mode }\end{array}$ & $\begin{array}{l}\text { Bowen et al. (2007) } \\
\text { Sambamurthy and Zmud (1999) }\end{array}$ \\
\hline IT Governance Process & Communication System & $\begin{array}{l}\text { Ali and Green (2009) } \\
\text { Huang et al. (2010) }\end{array}$ \\
\hline Relational Mechanisms & $\begin{array}{l}\text { Relational Culture } \\
\text { Attitudinal Commitment }\end{array}$ & Willson and Pollard (2009) \\
\hline
\end{tabular}


(Sambamurthy and Zmud, 1999). Decentralizing decision making allows divisional units to have more flexibility in customizing solutions to their needs. In addition, it enhances the responsiveness to divisional unit's IT needs.

As emphasized by the IT Governance Institute (2003), the setting up an IT strategy committee and an IT steering committee can contribute to an effective IT governance structure. The IT strategy committee, which comprises of board and non-board members, is a governing body for the organization's IT related decisions, operations and issues. Its main function is to lay out clear and precise roles and responsibilities which are fundamental elements for aligning IT-related decisions and operations. The role of IT steering committee is to drive the organization's ITrelated operations such as allocating IT resource, overseeing major IT projects, setting priorities, addressing IT-related issues and monitoring IT investments. It is imperative to appoint a governing body to manage and regulate these committees.

\section{Socio-Technical Factors Influencing IT Governance Processes}

Generally, IT governance processes entail IT management techniques for planning and implementing IT related decisions to support the alignment between business objectives and IT. The effectiveness of IT governance processes is determined by how well the committees can communicate with other parties on how to deliver IT strategies, how to implement IT policies, how to measure the expected outcomes and what types of performance indicators to be used (Weill and Ross, 2004). Furthermore, these authors assert that the fundamental factor which hampers the effectiveness of IT governance is a lack of understanding between business and IT people. Consequently, this has a negative impact on the collaboration among the relevant parties. This situation happens because there is an ineffective communication process.

A communication system plays a crucial role in facilitating an effective communication process through which IT strategies, policies and procedures can be accurately assimilated (Weill and Ross, 2004). In the study of Ali and Green (2009,) they found that there was a positive relationship between corporate communication systems and the effectiveness of IT governance. Typically, a corporate communication system entails both the synchronous and asynchronous flow of communication. Synchronous communication takes place when all collaborative partners can access or exchange information at the same time whereas asynchronous communication takes place when all collaborative partners access or exchange information and provide feedback at different points in time. A combination of both types of communication allows the simultaneous flow of information in multiple directions and across functional boundaries (Chi and Holsapple, 2005) can engage the relevant parties to be more active in the implementation and management of IT processes and related activities and procedures (De Haes and Van Grembergen, 2004).

Some studies have suggested that more communication channels can have a positive impact on the quality and quantity flow of information. For example, Huang et al.'s (2010) recent case study depicted that more communication channels allowed the relevant parties to have greater accessibility to IT governance policies, guidelines and practices. Similarly, the study of Bowen et al. (2007) asserted that having Intranet as the only organizational communication channel would not necessary enable better communication of IT governance processes and decision. Rather, it required more communication channels to assimilate and disseminate information which enables a wider degree of IT governance transparency thus a shared understanding between business and IT can be established (Weill and Ross, 2004).

\section{Socio-Technical Factors Influencing Rela- tional Mechanisms}

Typically, relational mechanisms are critical to the effectiveness of IT governance as they are the means in aligning business and IT through a shared understanding between business and IT people. To be able to deliver 
a shared understanding for IT governance structures and processes, strong working relationships between the people are crucial (De Haes and Van Grembergen, 2004). This is because closely-knitted relationships steer the people to possess a collaborative behaviour which can eradicate disagreements, uncoordinated actions and other problems that obstruct collaboration (Peterson, 2004).

There is evidence in the literature that organizational culture plays an important role in influencing collaborative behaviour. O'Reilly (1989) argues that a strong organizational culture can improve the co-ordination processes, cohesive decision-making process and increase the level of attitudinal commitment. Significantly, these factors are critical in strengthening the effectiveness of IT governance structures and processes. In addition, organizational culture can also determine the way people share information. According to O'Reilly (1989), a strong organizational culture can envelope a set of shared norms and values which can encourage open flow of information. Ultimately, an information-sharing culture will be created.

However, having strong organizational culture is not a sufficient condition for the effectiveness of IT governance. It is anticipated that commitment of the board and non-board members, as a social factor, plays a role as well. As advocated from the literature that an active participation of the committees can have a positive influence on IT governance (De Haes and Van Grembergen, 2004; Sambamurthy and Zmud, 1999; Weill and Ross, 2004). When the board and non-board members are more committed to their functional roles, this would engender better decisional and operational performances. According to Cullen et al. (2000), there two dimensions of commitment: calculative commitment and attitudinal commitment.

Calculative commitment refers to the economic side of commitment which is driven by the benefits of investment in relation-specific, non-recoverable assets in the alliance. The second dimension is known as attitudinal commitment which refers to an emotional or affective component; it is driven by the feelings and attitudes of the participants to the specific relation. It is more desirable for the committee members to possess attitudinal commitment as they would allocate most of the time to administer their functional roles (Chen, 2001). That is to say, the board and non-board members are actively participating in overseeing the collaborative network's IT governance.

\section{Research Findings and Analysis}

Our findings suggest that the three aspects of IT governance contributed to a better understanding of how a collaborative network implements IT governance. The findings also confirm that typical socio-technical factors influenced the effectiveness of a collaborative network IT governance.

\section{Analysis of IT Governance Structure}

It is advocated that organizational size can influence the adoption of IT governance structure (Huang et al., 2010; Peterson, 2004; Sambamurthy and Zmud, 1999). If the organization is an SME then it would be more appropriate to adopt a centralized IT governance mode, while it is more feasible for a large multi-international organization to adopt a decentralized IT governance mode. As the members in a collaborative network can range between SMEs and large multi-national organizations, it would seem more appropriate to deploy a hybrid governance structure. Evidence from the case study supports this notion. We observed that the PHP had adopted a federal governance structure. The federal governance structure enabled the collaborative network to benefit from "the best of both worlds" that produced a positive impact on IT governance (Peterson, 2004). More importantly, it benefited the collaborative network to have better decision making arrangements as the allocation of IT related decision making rights and responsibilities was equally shared among the various stakeholders.

The PHP collaborative network was comprised of eight organizations therefore it was vital for the collaborative partners to identify 
who were responsible in making certain IT associated decisions and how these decisions would be executed (Weill, 2004). The PHP network's decision making structures had to reduce uncertainty and ambiguity arising from the assimilating, disseminating and communicating of information and knowledge that were crucial for facilitating the collaborative network's business and operational processes. The federal IT governance mode enabled the PHP network's decision making structure to achieve standardization under centralization and flexibility under decentralization (Peterson, 2004).

The Health Technology Consortium had set up an IT steering committee to oversee the federal inter-organizational IT governance structure. The steering committee comprised of ITConsult, Primary Health Organization, Health Systems Provider A, Health Systems Provider B, Health Information Provider A and Health Information Provider B. Accordingly, decision making in relation to the direction, designing and building of the health portal were centralized within the network. That is to say, the IT steering committee would work together with the Health Technology Consortium and Software Company to co-ordinate all IT operations. While, a decentralized decision structure was observed at a functional level as each organization was responsible for a specific function of the PHP.

Though Health Technology Consortium had formulated a scoping document in detailing the roles and responsibilities nevertheless it was inadequate to co-ordinate the health portal related activities and operations. Apparently, there was no one to regulate the steering committee in managing the project such as setting priorities and addressing health portal-related issues. This only happened at a later stage when ITConsult was appointed as the project manager. As acknowledged by ITConsult's Project Consultant Manager, it was critical to identify a leader for the project before its commencement:

"One of the reasons it (PHP project) was slipping was because there was no strong project management at the start. I came half way. My view is that it was not clear who the project manager was in fact and which organization had responsibility for project management"

Evidence from the study suggests that it is important to involve a governing body to regulate the committee. As reported, the appointment of ITConsult enabled an improved co-ordination of the health portal related activities such as setting up priorities and meeting datelines.

\section{Analysis of IT Governance Processes}

It was evident from the study that the PHP project had deployed both synchronous and asynchronous communication channels to facilitate the IT governance processes. Faceto-face meetings and teleconferencing, as the synchronous communication channels, were utilized for the facilitation of information related to the health portal's guidelines, practices, progress and datelines, while asynchronous communication channels such as Groove (a shared workplace) and e-mail were used to post documents associated with the health portal's technical proof of concept.

The findings reflected that there was ineffective communication between the stakeholders who were responsible for managing the collaborative network and those who were responsible for developing the health portal. This was because the collaborative network only deployed synchronous and asynchronous communication channels to communicate information in relation to technical related activities. Thus, the IT partners did not have an explicit idea of what the project's non-technical activities were and how they had been carried out. As observed, the failure to develop a communication structure to support the delivery of non-technical information had obstructed shared understanding between management and IT people:

"The technology platform like Groove was good but the developers were using it for technical communication. The wider project and important stuffs were never got communicated. Mainly when I looked at Groove it was not used too much for communication. It 
IT Governance in Collaborative Networks: A Socio-Technical Perspective / Chong and Tan

was used to share documents around. It took away the need to email everybody all the time. There was no communication in that sense." (CEO of Health Systems Provider A)

\section{Analysis of Relational Mechanisms}

As a collaborative network encompasses more than one organization, it would entail different sets of organizational norms and values. Beugelsdijk et al. (2009) contended that differences in organizational culture may encumber the development of a common empathy which consequently would induce a negative effect on the collaborative relationship. The extent to which the organizational cultures differ in a collaborative network is known as cultural distance. A wider cultural distance will bring about lower levels of integration and cohesion in a collaborative network (Shachaf, 2008). As a result, it will lead to inefficient flows of information and a constrained communication process within the network. Very often, an inefficient and ineffective communication process will undermine the collaborative relationship. Therefore, it is crucial for a collaborative network to cultivate a relational organizational culture (Beugelsdijk et al., 2009).

A relational culture "unifies" the subcultures in the collaborative network. This characteristic has been recognised as a "strong" culture as it can foster a better co-ordination and integration of each subculture's assumptions, beliefs and practices. Sources of integration range from limited set of rules about when and how to agree and disagree, to a relational culture with high conformity with little or no dissent. Relational culture plays an important role in encouraging network members to cultivate mutual values and norms that can engender more cohesive IT related decisions making consequently better co-ordinated processes in aligning business and IT. Furthermore, relational culture can encourage an information-sharing environment which is imperative for an effective delivery of IT governance structures and processes (Weill and Ross, 2004).

It was observed that a relational organizational culture was developed in the initial stage of the PHP project. There were two factors that drove the organizations to have a mutual norm and value. The organizations shared a social goal which was to build a successful health portal and ultimately it could benefit the New Zealand healthcare consumers. The Business Development Manager of Health Information Provider A commented: "It was about let's start this and knowing what was going to be the endpoint was something going to be beneficial for you as a New Zealander managing your health. And most people thought that was a brilliant idea". Similarly, the Health Account Sector Manager of Software Solution Provider stated: "We might think this Proof of Concept is part of our social responsibility to participate in a program like this". In addition to a social objective, the organizations also shared an economical objective which was each organization could own a proportion of the health portal in accordance to their investment.

Nevertheless, the project did not manage to sustain the relational organizational culture as it progressed. As this was a non-equity innovative collaboration, the protection of the intellectual property (IP) had to be detailed in the contracts. As there was no formal agreement in protecting the organizations' control of the IP for the health portal, it consequently inflicted different sets of norms and values. As emphasized by the Business Development Manager of Health Information Provider A: "It was never having a cohesive effort probably it was because one player involved in the project team had different goals and objectives". More significantly, this led one particular organization to adopt an opportunistic behaviour which undermined the relational culture.

In general, the collaborative network had been characterized as more calculative committed rather than attitudinal dedicated. At the initial stage of the project, the organizations had a mutual understanding that they had a shared goal: to reinforce New Zealand's patient-centred healthcare system. Certainly, this shared social goal had fostered the organizations' attitudinal commitment in developing a successful national health portal. 
"It really comes back to the beginning that we had a good understanding and we all thought that we had good feeling about a common goal as a shared goal and vision. Everyone is so driven by their ideas and goal in producing the national health portal that they believed in" (Chief Information Officer, Primary Health Organization)

However at some stage in the project, calculative commitment had dominated attitudinal commitment. The organizations had become less attitudinal committed when they realized the business model had not yet been developed. The uncertainty about whether to be able to reap the economic gains had led the collaborative partners to reduce their contribution efforts henceforth they became more calculatively committed to the network.

\section{Discussion}

The aim of the pilot case study was to explore how IT governance was established in a collaborative network context. The study illustrated that the implementation of IT governance was facilitated by IT governance structures, processes and relational mechanisms. Furthermore, the study underlined the crucial role played by the socio-technical factors in reinforcing the three aspects of IT governance. From the analysis, we present a conceptual model.

The collaborative networks' processes and operations would be more co-ordinated as the partners had a good understanding of their roles and how they could be involved in the IT governance processes. Furthermore, the hybrid governance mode allowed the IT organizations to have more flexibility in building the health portal. Despite setting up an IT steering committee to manage, direct and oversee the health portal related activities, the health portal related activities and operations were still poorly co-ordinated. The interviewees agreed that there was no leader in regulating the project. Thus, the appointment of a governing body, as a social factor, can play a crucial role in reinforcing IT governance structure. This finding is consistent with the study of De Haes and Van Grembergen (2004) which found that the effectiveness of IT governance was positively influenced by the involvement of an IT governing body such as a IT business steering committee.

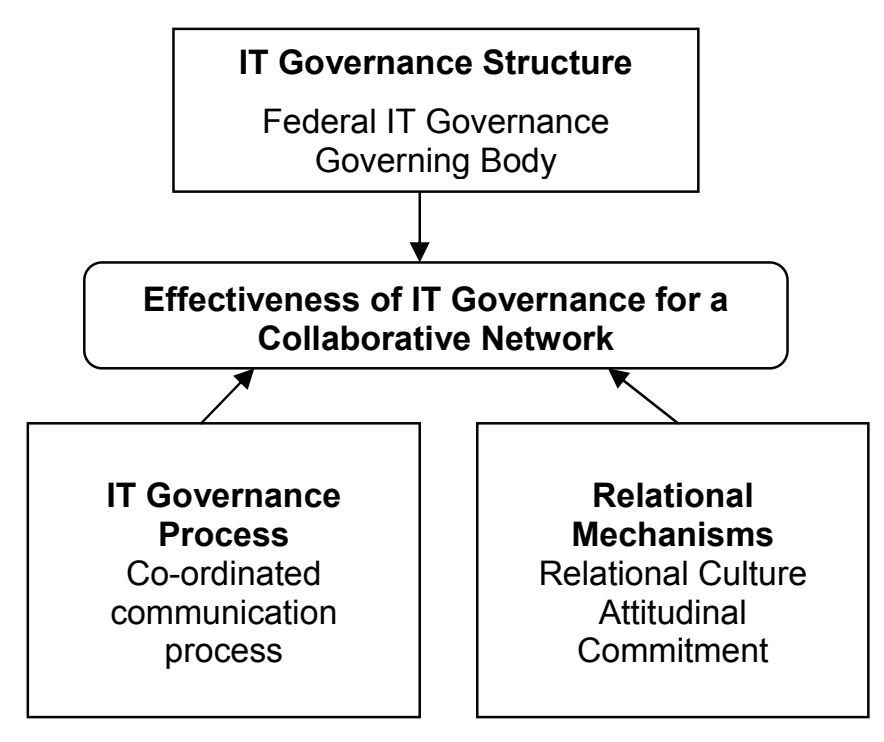

Figure 1 - Conceptual Model 
The literature generally supports the notion that effective communication process will have positive effect on the IT processes. Huang et al. (2010) further affirmed that the deployment of more communication channels would improve the effectiveness of IT governance. However the study found that the number of communication channels had no direct impact on the collaborative network IT governance. Rather, it was how these synchronous and asynchronous channels were deployed to facilitate the processing of information so as to avoid information gaps. The PHP project had four communication channels and yet information in relation to other non-technical issues had not been efficiently disseminated to the IT partners. The project's communication channel became mainly a repository system for delivering and sharing technical information and issues related to project management had not been discussed. Consequently the lack of information richness obstructed the effective delivery of the collaborative network's overall IT related activities. Thus, this study suggests that it is essential to identify a person to co-ordinate and manage the communication process so that the collaborative partners can be more actively and closely interacted in communicating on the delivery and implementation of IT strategies and policies.

The study has clearly demonstrated the impact of social factors on relational mechanisms. If the characteristic of the collaborative network is non-equity then proper documentation ought to be formulated in protecting each organization's IP. Apparently, the failure of such an act had disabled a relational culture to be cultivated. Consequently, this affected the delivery of the collaborative networks' IT governance processes. Moreover, it was crucial to cultivate the committee members to develop a sense of attitudinal commitment so that they would sustain their active participation throughout the project.

\section{Conclusions}

This study presents a model of how a collaborative network can establish effective IT governance and illustrates it with a pilot case study. It suggests that a collaborative network IT governance represents a sociotechnical system, an organizational work system that is to be facilitated by both technical and social systems. In addition, sociotechnical factors are essential to the effectiveness of IT governance in a collaborative network. More significantly, the study suggests that there is a direct relationship between the socio-technical factors and IT governance structures, processes and relational mechanisms. It contends that organizational size and identification of a governing body would influence IT governance structures; effective co-ordinated communication would influence IT governance processes and relational culture and attitudinal commitment would influence relational mechanisms.

For practitioners, this study provides useful insights to collaborative organizations in how they can ensure the effectiveness of IT governance. The case study underpins that the adoption of a federal governance structure is more appropriate for a collaborative network. It is suggested to identify a governing body at the start of the collaboration to regulate the steering committee. Importantly, such governing body needs to establish a co-ordinated communication process to assimilate and disseminate IT governance policies and procedures to the collaborate partners. Furthermore, it is recommended to the practitioners that attitudinal commitment ought to be cultivated so that collaborative partners can entail active participation throughout the IT project implementation. A summary of the findings is provided in Table 3.

This study has two limitations. First, the social factors are rather one-sided perspective as only attitudinal commitment and relational organization culture are examined. Future research can consider the perception of trust as a social factor. Second, as this case study was a single case study therefore it might entail a problem of generalization. Rather, a study of multiple cases from the health industry could have conducted hence a better reflect on the effectiveness of IT governance for a collaborative network. 
Table 3 - Summary of Findings

\begin{tabular}{|c|l|}
\hline IT Governance Elements & Learning from this study \\
\hline IT Governance Structure & $\begin{array}{l}\text { A focal organization has to be identified to structure the project's decision } \\
\text { making process and to manage operational collaborative activities. }\end{array}$ \\
\hline IT Governance Process & $\begin{array}{l}\text { It is vital to co-ordinate both synchronous and asynchronous communica- } \\
\text { tion to facilitate all technical and non-technical related information among } \\
\text { all stakeholders. }\end{array}$ \\
\hline Relational Mechanisms & $\begin{array}{l}\text { Relational culture and attitudinal commitment have to be cultivated to sus- } \\
\text { tain engagement of stakeholders when the collaboration entails a non- } \\
\text { equity innovation. }\end{array}$ \\
\hline
\end{tabular}

\section{References}

Ahuja, G. (2000). "The duality of collaboration: inducements and opportunities in the formation of interfirm linkages," Strategic Management Journal, vol. 21, no. 3, pp. 317-343.

Ali, S. \& Green, P. (2009). "Effective information technology (IT) governance mechanisms: An IT outsourcing perspective," Information Systems Frontiers

Ayra, B. \& Lin, Z. (2007). "Understanding Collaboration Outcomes From an Extended Resource-Based View Perspective: The Roles of Organizational Characteristics, Partner Attributes, and Network Structures," Journal of Management, vol. 33, no.5, pp.697723.

Benbasat, I., Goldstein, D.K. \& Mead, M. (1987). "The Case Research Strategy in Studies of Information Systems", MIS Quarterly, vol. 11, no.3, pp. 369386.

Beugelsdijk, S., Koen, C. \& Noorderhaven, N. (2009). "A dyadic approach to the impact of differences in organizational culture on relationship performance," Industrial Marketing Management, vol. 38, pp. 312-323.

Bowen, P.L, Cheung, M-Y.D. Cheung \& Rohde, F.H. (2007). "Enhancing IT governance practices: a model and case study of an organization's efforts," International Journal of Accounting Information Systems, vol.8, no.3, pp. 191-221.

Brown, C.V. (1997). "Examining the Emergence of Hybrid IS governance Solutions: Evidence from a Single Case Site," Information Systems Research, vol. 8, no. 1, pp. 69-95.

Brown, A. and Grant, G. (2005). "Framing the Frameworks: A Review of IT Governance Research," Communication of the AIS, vol. 15, pp. 696-712.

Chen, I.J. (2001). "Planning for ERP systems: analysis and future trend," Business Process Management Journal, vol.7, no.5, pp. 374-386.

Chi, L. \& Holsapple, C.W. (2005). "Understanding computer-mediated interorganzational collaboration: a mode and framework," Journal of knowledge Management, vol. 9, no. 1, pp. 53-75.

Croteau, A.M. \& Bergeron, F. (2009). "Interorganizational governance of information technology", Proceedings of the 42nd Hawaii International Conference on System Sciences.

Cullen, J.B., Johnson, J.L. \& Sakano, T. (2000). "Success through commitment 
IT Governance in Collaborative Networks: A Socio-Technical Perspective / Chong and Tan

and Trust," Journal of World Business, vol. 35, no.3, pp. 223-240.

De Haes, S. \& Van Grembergen, W. (2005). "IT Governance Structures, Processes and Relational Mechanisms: Achieving IT/Business Alignment in a Major Belgian Financial Group," Proceedings of the $38^{\text {th }}$ Annual Hawaii International Conference on System Sciences, pp. 237.

Eisenhardt, K.M. (1989). "Building theories from case study research", Academy of Management Review, vol.14, pp. 532-550.

Fink, L. (2007), "Coordination, Learning, and Innovation: The Organizational Roles of E-Collaboration and Their Impacts," International Journal of eCollaboration, vol. 3, no. 3, pp. 53-70.

Fischer, F. (1993). "Reconstructing policy analysis: A postpositivist perspective," Policy Sciences, vol. 25, pp. 333-339.

Kingsford, R., Dunn, L., \& Cooper, J. (2003), "Information Systems, IT Governance and Organisational Culture," $14^{\text {th }}$ Australasian Conference on Information Systems, pp.1-14.

Hekkala, R., Urquhart, C., Newman, M. \& Heiskanen, A. (2010). "Understanding Governance Issues in an InterOrganisational IS project," Proceedings of the 21st Australasian Conference on Information Systems.

Hemphill, T.A. and Vonortas, N.S. (2003). "Strategic Research Partnerships: A Managerial Perspective," Technology Analysis \& Strategic Management, vol. 15 , no. 2, pp. 255-271.

Huang, R., Zmud, R.W. \& Price, R.L. (2010). "Influencing the effectiveness of IT governance practices through steering committees and communication policies," European Journal of Information Systems, vol. 9, pp. 288-302.

ITGI. (2003). IT Governance Institute, briefing on IT governance, $2^{\text {nd }}$ edition, re- trieved on Board1August, 2010, from www.itgi.org.

Kim, C., Jahng, J. \& Lee, J. (2007). "In Empirical Investigation into the UtilizationBases Information Technology Success Model: Integrating taskperformance and social influence perspective," Journal of Information Technology, vol. 22, no.2, 152-160.

Liu, G., Shah, R. \& Schroeder, R.G. (2006). "Linking Work Design to Mass Customization: A Sociotechnical Systems Perspective," Decision Sciences, vol. 37, no. 4, pp. 519-545.

Luftman, J.N. \& R. Kempaiah. (2008). "Key Issues For IT Executives 2007," MISQ Executive, vol. 7, no.2, pp. 99-112.

Merhout, J.W. \& Havelka, D. (2008). "Information Technology Auditing: A ValueAdded IT Governance Partnership between IT Management and Audit," Communications of the Association for Information Systems, vol. 23, 463482.

O' Reilly, C. (1989). "Corporations, Culture, and Commitment: Motivation and Social Control in Organizations," California Management Review, vol. 31, pp. 9-25.

Orlikowski, W. J. \& Barley, S. R. (2001). "Technology and Institutions: What Can Research on Information Technology and Research on Organizations Learn from Each Other?" MIS Quarterly, vol. 25, no.2, pp.145-165.

Patton, M. Q. (1999). "Enhancing the quality and credibility of qualitative analysis", Health Serv. Res., vol. 4, no.5, pp.1189-1208.

Peterson, R. (2004). 'Crafting information technology governance', Information Systems Management, vol.21, no.4, pp. 7-22.

Pettey, C. (2012). "Gartner Says Worldwide IT Spending to Grow 3.7 Percent in 2012, " URL:http://www.gartner.com/it/ 
age.jsp?id=1888514

Rycroft, R.W. \& Kash, D.E. (2002), 'Path dependence in the innovation of complex technologies', Technology Analysis and Strategic Management, vol. 14, no. 1, pp. 21-35.

Sambamurthy, V. \& Zmud, R.W. (1999), 'Arrangements For Information Technology Governance: A Theory Of Multiple Contingencies', MIS Quarterly, vol.23, no.2, pp. 261-290.

Shachaf.P. (2008), 'Cultural diversity and information and communication technology impacts on global virtual teams: An exploratory study'. Information and Management, vol. 45, pp. 131-142.

Somers, T.M. \& Nelson, K.G. (2004), 'A taxonomy of players and activities across the ERP project life cycle', Information \& Management, vol. 41, pp. 257-78.

Strauss, A. \& Corbin, J. (1998), 'Basics of Qualitative Research: Techniques and Procedures for Developing Grounded Theory', London: Sage

Taylor, S. (2005), 'An operations perspective on strategic alliance success factors: An exploratory study of alliance managers in the software industry', International Journal of Operations and Production Management, vol.25, no.5, pp.469-490.

Trist, E.L. (1981), 'The Socio-Technical Perspective. The evolution of sociotechnical systems as a conceptual framework and as an action research program. In van de Ven A. \& Joyce W.F. (eds.) Perspectives on Organization Design and Behaviour. Wiley, pp. 49-75.
Van Grembergen, W., De Haes, S., \& Guldentops, E. (2004), 'Structures, Processes and Relational Mechanisms for IT Governance,' Strategies for Information Technology Governance, Idea Group, London, pp. 1-36.

Van Grembergen, W., De Haes, W., \& Amelinckx, S.I. (2003), 'Using COBIT and the Balanced Scorecard as Instruments for Service Level Management,' Information Systems Control Journal, vol. 4, pp. 56-62.

Webb, P., Pollard, C. \& Ridley, G. (2006), 'Attempting to Define IT Governance: Wisdom or Folly? Proceedings of the 39th Annual Hawaii International Conference on System Sciences, vol. 8, IEEE Computer Society

Weill, P. (2004), 'Don't Just Lead Govern: How Top-Performing Firms Govern IT', MIS Quarterly Executive, vol.3, no.1, pp. 1-17.

Weill, P. \& Ross, J.W. (2004), 'IT governance: How Top Performers Manage IT Decision Rights for Superior Results', Watertown, MA: Harvard Business School Press.

Wilkin, C.L. \& Riddett, J. (2009), 'IT governance challenge in large not-for-profit healthcare organization: The role of intranets', Electronic Commerce Research, vol. 9, pp. 351-374.

Willson, P. \& Pollard, C. (2009), 'Exploring IT Governance in Theory and Practice in a Large Multi-National Organization in Australia', Information Systems Management, vol.26, pp.98-109.

Yin, R. (2003), 'Case Study Research: Design and methods' (Third Edition), Beverly Hills, CA: Sage. 
IT Governance in Collaborative Networks: A Socio-Technical Perspective / Chong and Tan

\begin{abstract}
About the Authors
Josephine Chong is currently a $\mathrm{PhD}$ candidate in Department of Business Information Systems at Auckland University of Technology. She holds a Bachelor Degree in Finance and Economics from the University of Auckland and Master of Social Sciences from the National University of Singapore. Her research interests cover collaborative networks, resources and capabilities, governance and e-Health. Her work has been published in Journal of Business Research, Americas' Conference on Information Systems and Australasian Conference on Information Systems.

Dr Felix B Tan is Professor of Information Systems and Head of the Department of Business Information Systems in the Faculty of Business and Law, Auckland University of Technology, New Zealand. He served as the
\end{abstract}

Editor-in-Chief of the Journal of Global Information Management from 1998 to 2012 and was on the Council of the Association for Information System from 2003 to 2005. Dr Tan is internationally known for his work in the global IT field. His other research interests include IT user behaviour and the management of IT. Dr Tan has published in MIS Quarterly, Information \& Management, Communications of the AIS, Communications of the ACM, IEEE Transactions on Engineering Management, IEEE Transactions on Personal Communications, Information Systems Journal, Journal of Information Technology, International Journal of Electronic Commerce, as well as other journals and refereed conference proceedings. 